\title{
Rat bite injury to the eyelids in a 3-month-old child
}

\author{
W N WYKES \\ From St Woolos' Hospital, Newport, Gwent
}

SUMMARY A 3-month-old child received severe rat bite injuries to the face, including subtotal loss of upper and lower lids of one eye. The presentation and management are discussed.

Animal bite injuries to the face are not uncommon and are most likely to be caused by dogs.' The lips, nose, or cheek are the commonest sites, though most ophthalmologists will have seen dog bites of the lids, often involving tears of the inferior canaliculous. ${ }^{2}$ Rodent bites of the face are, however, rare in Great Britain. Rat bite injuries are sometimes seen in babies in some Third World countries, where the mother leaves the baby at the side of the field in which she is working (Laserna $\mathbf{N}$, personal communication). This is the first case reported in Britain of a severe rat bite injury to the face, with consequent problems in management.

Correspondence to W N Wykes, FRCS, St Woolos' Hospital, Newport, Gwent NPT 4SZ.

\section{Case report}

A 3-month-old boy presented as an emergency in March 1985 . His family lived in a country cottage in Gwent, South Wales. His mother had placed him in his cot in the morning while she attended to her older son downstairs. On hearing his cry she went upstairs and found him lying in his cot with severe lacerations to the left side of the face (Fig. 1).

The patient was promptly taken to the operating theatre, where extensive loss of lid tissue of the left eye was found. There was only a quarter of the normal tissue of both lids remaining laterally, the rest of the skin, tarsal plate, and tarsal conjunctiva having been removed. There were also three full-thickness
Fig. 1 Facial injuries from rat bites, March 1985.

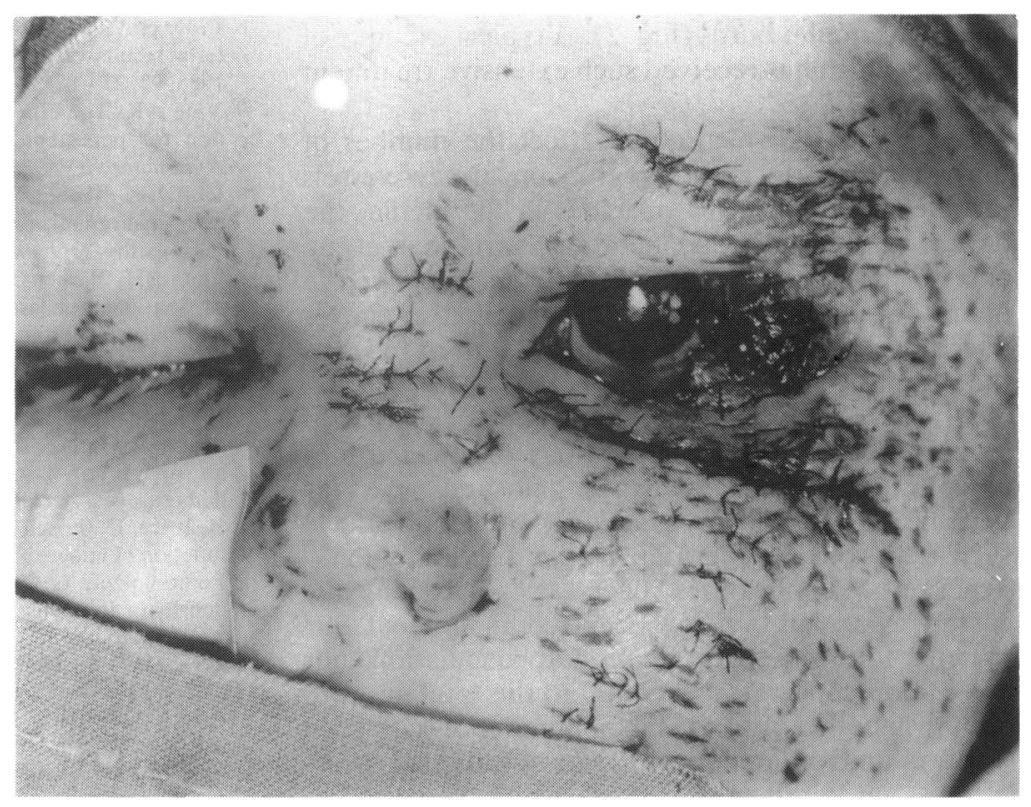




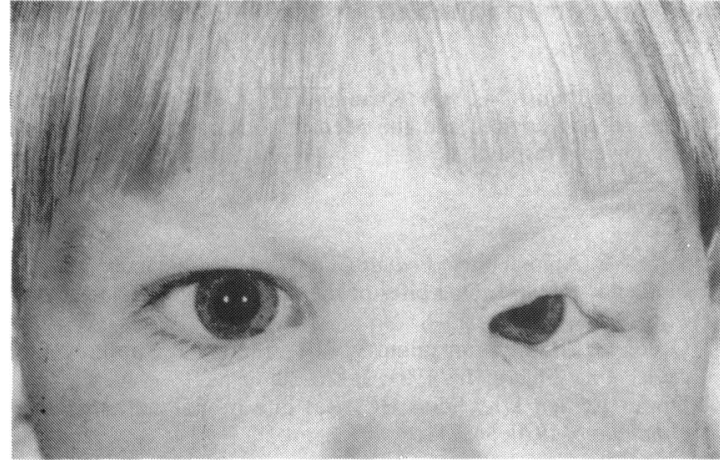

Fig. 2 Appearance before cosmetic surgery, April 1986.

lacerations below the left eye (repaired by the time the photograph was taken) and multiple wounds over the left side of face. The bulbar conjunctiva was damaged, but the globe itself was intact.

A plastic surgeon was involved from the start, as it was obvious that there would be long-term lid complications. The remnants of normal lid tissue were mobilised, and the conjunctiva used to cover the eye to prevent exposure of the cornea. A postauricular (Wolfe) graft was used to cover the eye completely. Despite the severity of the wounds, the baby did not develop any infection and was discharged a few days later.

The parents had originally thought that the injuries were due to a ferret which had been seen near the cottage. This was subsequently caught and killed, and the body, with photographs of the child's injuries, were sent to a forensic dentist at the School of Dentistry, Cardiff, who concluded that the injuries could not have been from a ferret but were almost certainly due to a rat.

By three weeks after the injury the Wolfe graft had sloughed and part of the cornea had become exposed, but was not ulcerated. Three months after the injury an examination under anaesthetic showed that adequate fornices had reformed, that the cornea was intact, and that it showed no staining with fluorescein.

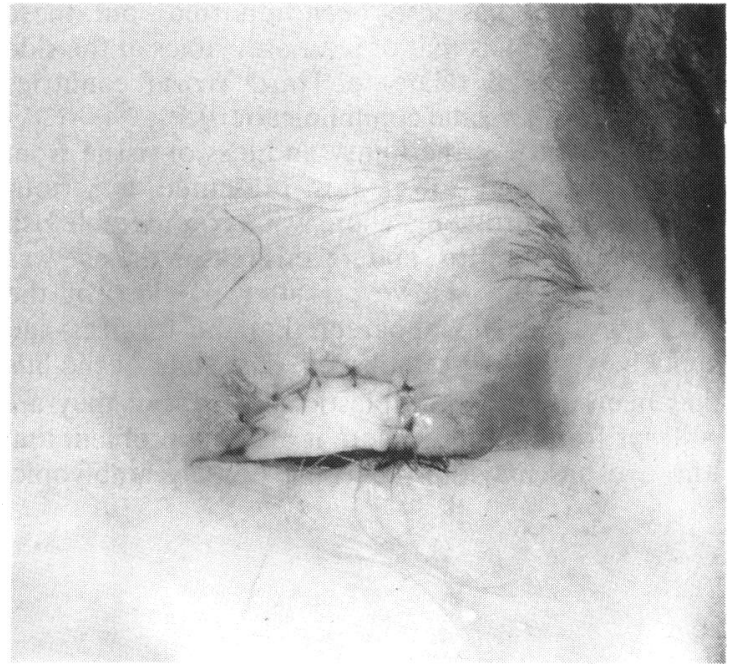

Fig. 3 Composite graft sutured in place, April 1986.

Five months after injury, at age 8 months, there was a marked left convergent squint with no response to the Catford-Oliver drum in that eye compared with a good response in the right eye. The left convergence was very variable. After five months of occlusion to the right eye the squint was still very variable and the left eye showed response to small toys.

Thirteen months after injury a composite graft from the left ear was performed to make good the vertical defect in the upper lid (Figs. 2, 3). This has improved the upper lid considerably, but the child still has some blepharophimosis, with some vertical and horizontal loss of tissue (Fig. 4). He has a residual dense left amblyopia, and further occlusion to the right eye is planned.

\section{Discussion}

This case report is unusual in both nature and severity. Rat bites may involve the face, particularly when the victim is sleeping, and orbital cellulitis due

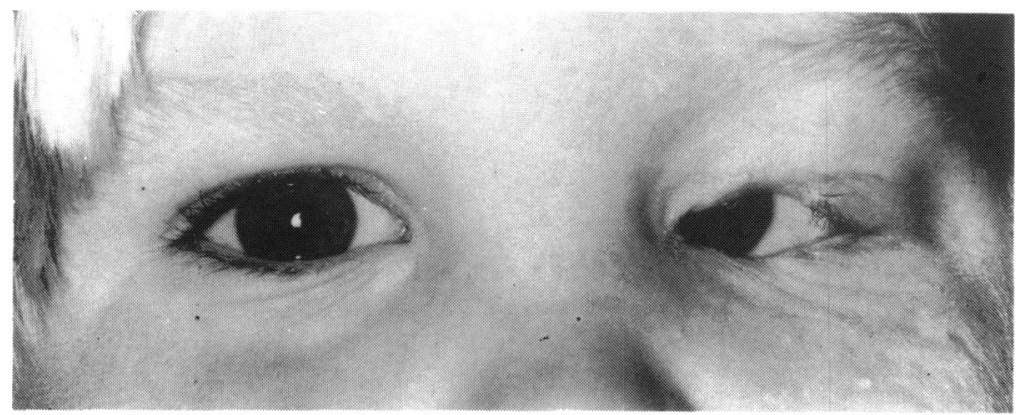

Fig. 4 Cosmetic appearance, August 1986. 
to a rat bite has also been reported, but these reports, as well as that of injury to babies at the side of the field, all relate to Third World countries (Laserna N, personal communication)..$^{34}$

The severity of the injury and loss of tissue from both upper and lower lids presented a serious management problem. There was a considerable risk of exposure keratitis, and for this reason the eye was initially covered. However, after the loss of the Wolfe graft it was apparent that the fornices had quickly become re-established. The state of the lids has been improved by plastic surgery, but they are still far from normal. There is also the problem that the eye has inevitably become densely amblyopic, and further orthoptic treatment will be required to correct this.

The author thanks Mr M Y Khan and Mr A G Karseras for their assistance and advice, and the Medical Illustration Department, Royal Gwent Hospital.

\section{References}

1 Jaffe AC. Animal bites. Pediatr Clin North Am 1983; 30: 405-13.

2 Palmer J, Rees M. Dog bites of the face: a 15 year review. $B r J$ Plast Surg 1983; 36: 315-8.

3 Ordog GJ, Balasubramanium S, Wasserberger J. Rat bites: fifty cases. Am J Emerg Med 1985; 2: 126-30.

4 Diwan R, Sen DK, Sood GC. Rat bite orbital cellulitis. $\mathrm{Br} J$ Ophthalmol 1970; 54: 211.

Accepted for publication 10 March 1988. 